Narrative review:

\title{
Rethinking physiotherapy for patients with fibromyalgia \\ - lessons learnt from qualitative studies
}

Authors, professional and academic affiliation:

Anne Marit Mengshoel, RPT, PhD, Professor ${ }^{1}$

Hedda Eik Grape, RPT, PhD student ${ }^{1}$

Department:

${ }^{1}$ Institute of Health and Society, Medical Faculty, University of Oslo, Norway

Corresponding author:

Professor Anne Marit Mengshoel,

Dept of Health Sciences, Medical Faculty, University of Oslo, Box 1089 Blindern, 0317 Oslo, Norway

Phone no: +4722845375

e-mail: a.m.mengshoel@ medisin.uio.no

\section{Keywords:}

Fibromyalgia - illness - recovery - physiotherapy - patient experiences - review

The work is not supported by any grants.

Article word count: $\mathbf{4 6 7 8}$ (including reference list - max 5000)

Abstract word count: 230 (max 250) 


\section{Abstract}

Background: Fibromyalgia (FM) is characterized by chronic, widespread musculoskeletal pain, extensive fatigue and an array of other symptoms. Cure is not expected, and patients have to learn to live with the illness. During the last years several studies have examined how it is like to live with FM from a patient's point of view. These findings may help physiotherapists to better understand the challenges faced by patients.

Objective: To describe what it is like for patients to live with FM and discuss how this may inform physiotherapy practice.

Design: A systematic literature search of qualitative studies up till May 2016 was conducted, and 93 papers were read. The focus was on patients' experiences of symptoms and how they managed everyday life.

Results: Incomprehensible, unpredictable symptoms of FM intrude and disturb everyday life. The body is constantly monitored by patients on a day-to-day basis according to fluctuations in pain and energy levels, and habits and routines of daily life are adapted to these shifts. With other words, the connection between body, self and daily life is ruptured. In contrast, those having recovered from FM had found out what they could tolerate during a day and spent long time in rebuiding a life worth living.

Conclusion: The present paper presents an argument that living with FM calls for a rather complex personal healing process that should be recognized and supported by physiotherapists. 


\section{Introduction}

Fibromyalgia (FM) is a common condition being estimated to occur in about $3-4 \%$ of the adult population, ${ }^{1}$ mostly among women. However, recent revised diagnostic criteria may include more men in the future. ${ }^{2}$ Accordingly, the prevalence rate is likely to rise. The main characteristics of FM is widespread, chronic musculoskeletal pain, excessive fatigue, nonrestorative sleep, activity intolerance, irritable bowel, headache, cognitive problems, depression and multiple limitations in daily life. ${ }^{2-5}$ The etiology is unknown, and the pathogenesis is related to hypersensitivity of the central nervous system due to changes in central pain modulation mechanisms. ${ }^{6}$ This means that patients may find normally nonpainful stimuli painful and normally painful stimuli to be more intensive than healthy people do. The aberrant nociceptive processing can not explain the complexity of the complaints reported by patients with FM, though.

FM can not be verified by any objective findings on laboratory and radiological examinations. The diagnosis is set based on the presence and severity of symptoms, ${ }^{2,7}$ and the diagnosis is often arrived at after excluding several other diseases. ${ }^{8}$ Evidence-based guidelines recommend pharmaceutical management to modulate either ascending or descending pain processing mechanisms within the central nervous system, conditioning exercise to improve physical capacity and avoid a sedentary life style, and cognitive therapy to improve coping, modify maladaptive thoughts and behaviors, and promote a healthy life style. ${ }^{9}$ However, as the effect sizes of these interventions are rather small with respect to symptom relief and the effects do not last, ${ }^{10-12}$ the clinical relevance of these findings are questioned. ${ }^{13}$ The symptoms disturb patients' daily life, and FM is a common cause of sick leave and disability pension. ${ }^{14}$ Thus, FM has considerable impact on official budgets, and better interventions are highly needed. 
In a previous paper in this journal published in $2000,{ }^{15}$ we discussed physiotherapy management for patients with FM based on the quantitative literature up till then. In line with this review, today, physiotherapy modalities, such as exercise and health promotion programs, are included in evidence-based clinical guidelines. ${ }^{9}$ However, we often hear physiotherapists tell that their patients' do not comply well with such programs, and on the other hand patients may tell us that physiotherapists do not quite understand how it is like for them to live with FM. During the work of a meta-ethnography on diagnostic experiences of patients with FM including 28 scientific reports, ${ }^{16}$ a broad systematic search on qualitative studies was carried out in Medline ( $n=562)$, PsychInfo $(n=430)$, Cinahl $(n=290)$, AMED ( $n=95)$, and Social Science Citation Index ( $n=486)$ up to May 2016. The search terms are given in table 1 . The present narrative review is based on our close reading of 93 identified qualitative studies where we had a particular focus on patients' experiences of symptoms and everyday life. The objective of the present paper is to describe what it is like for patients to live with FM, and to discuss how this knowledge may inform clinical physiotherapy practice.

\section{Personal suffering that intrudes and disturbs social life}

In medical sociology the term 'disease' is defined as applying to the medical and 'illness' to the subjective aspects of human suffering. ${ }^{17}$ Illness covers both the experience of symptoms and the ways in which symptoms interfere with life. Personal experience of suffering is assumed to develop through reciprocal interactions between a patient, his or her social context and life situation. Thus, illness can disrupt an individual's biography and identity, as well as social relationships and roles. ${ }^{18-20}$

Incomprehensible and unpredictable symptoms. 'People over years come to know their bodies' pecularities, to understand its needs and language'. ${ }^{21, p .258}$ In health, people know their 
body and trust the information the body provides, and the body is usually taken for granted in daily life. In FM, bodily sensations, such as pain and excessive fatigue, make the body unfamiliar as the sensations are not anchored in meaning. The sensations are interpreted to signal that something is wrong. The sensations are experienced as diffuse and with a fluctuating severity. ${ }^{22-24}$ Pain is experienced as aggressive, ${ }^{25,26}$ and many factors may trigger pain, such as changes in the weather, unrefreshed sleep, physical and mental stress. ${ }^{3}$ Pain may also vary for no apparent reason, and although pain-free days may occur these days are not foreseen. ${ }^{27}$ Despite that it is difficult to cope with pain, fatigue is often found the most challenging to manage ${ }^{28}$ and is perceived to be overwhelming. ${ }^{29}$ Fatigue is described like 'heavy rain falling over them that is not possible to stop or relieve', 27,p7060 and is experienced quite differently from the usual tiredness they had before falling ill. ${ }^{30,31}$ Often fatigue cannot be explained by what the patients have been exposed to during a day or the time of the day. ${ }^{29-}$ 31 Thus, both the symptoms as such and the unpredictable fluctuations in severity make it difficult to keep up a normal life. ${ }^{32}$ By overdoing on good days, pain and fatigue can be rather bad the following day, and the body is perceived to take revenge. ${ }^{27}$ In other words, patients cannot trust their body anymore. Therefore, patients may describe their bodies as being treacherous ${ }^{24}$ or alien. $^{30}$

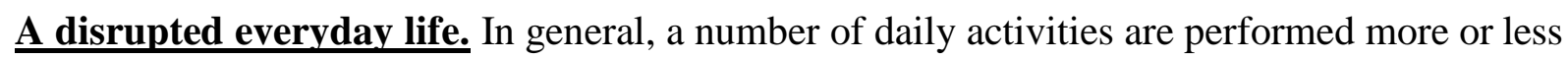
automatically, including habits and routines that are largely shaped by social roles, personal values and life expectations. In order to avoid becoming worse, patients carefully monitor their body and what they can tolerate to do on daily basis; ${ }^{22,33}$ so both pain itself and fear of pain interfere with existing habits and routines. ${ }^{34}$ Activities are planned in accordance with day-to-day symptom levels, and halted if they become worse. ${ }^{34,35}$ The lack of energy makes it challenging to carry out activities in everyday life, ${ }^{26,36}$ and the energy level is constantly 
monitored to determine how to spend their limited energy. ${ }^{27}$ Consequently, also everyday life becomes more or less unpredictable and ruled by symptoms, ${ }^{34,37,38}$ and to manage everyday life has become a struggle. ${ }^{39}$ The altered life situation can lead to grief over undone tasks and unfulfilled social obligations, and patients may be forced to delegate responsibilities to other people, and thereby alternating between independence and dependency on others. ${ }^{40}$ Their identity, social roles and relationships may be compromised; for example their identity as a competent employee or housewife. ${ }^{41,42}$ In other words, the coherence between body, self and society is ruptured. ${ }^{43}$

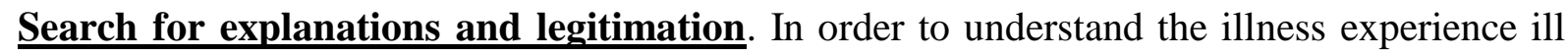
people usually seek medical explanations. They expect the diagnosis and medical knowledge to make sense of unfamiliar bodily sensations, validate that the sensations are 'real' and provide guidance on what to do. ${ }^{44}$ The journey towards getting a diagnosis might be strenuous and time-consuming for patients with chronic widespread pain as occasionally the diagnostic process includes numerous consultations and medical assessments by various medical specialists. ${ }^{45,46}$ In this process, several severe diseases are often excluded, ${ }^{47}$ and a European multicentre patient survey demonstrated that it often takes years before arriving at a diagnosis of FM. ${ }^{48}$ At last achieving the FM-diagnosis, patients are relieved that the illness is not fatal. ${ }^{49}$ But this relief wanes over time, as patients notice that there is not full consensus among health professionals about how the condition should be understood and managed. ${ }^{45,50}$ FM is invisible on medical assessments, and the validity of the diagnosis and realness of symptoms may be questioned by health professionals, including physiotherapists. ${ }^{47,50,51}$ Moreover, patients with FM do not necessarily look sick, so the condition is invisible in this way as well. ${ }^{28,49}$ Consequently, the patients' altered behaviour and inability to meet their former social obligations are difficult for others to understand and accept. Many patients are 
accused of malingering, to exaggerate symptoms that people normally experience from time to time, or to suffer from a psychological problem. ${ }^{52,53}$ Thus, in addition to manage inexplicable symptoms, the patients also have to manage the low legitimacy of the diagnosis of FM in various social contexts. ${ }^{16}$

A diagnosis is expected to be followed by efficient therapy leading to cure or at least palliation of symptoms. However, the strenuous time of searching for a diagnosis is now replaced by a period of trials and errors to find something that can help. However, when therapies are found inefficient, patients experience that health professionals lose interest and start to distrust them. ${ }^{54}$ By not becoming better, it is questioned whether the patients are following the therapeutic prescriptions and doing their best to recover. ${ }^{45}$ This means that patients have become a difficult case, ${ }^{53}$ and they can feel humiliated by health professionals ${ }^{55}$ and others. ${ }^{56}$ This situation may deprive patients of credibility and dignity, ${ }^{56}$ and the stigmatizing attitudes may add to the burden of living with FM. ${ }^{57}$

\section{A personal process of remaking a life beyond illness}

Recovery from acute illness usually means returning to the life before falling sick. But in chronic illnesses a disrupted life has to be healed implying that a patient has to create or remake a new normal life within the boundaries set by illness. ${ }^{58,59}$ For the patient, this involves finding out what kind of life is possible, restructuring patterns of living, getting used to new habits and routines, and redefining social roles and obligations.

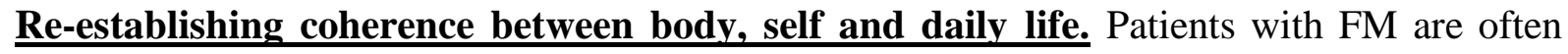
told that they have to learn to live with their illness. ${ }^{28}$ In order to do this they need to make sense of the altered body and how it interferes with daily life. For the individual, illness raises questions like: What is happening to me? What should I do? How can I get my life together 
again? What can I expect of the future? Such questions need to be answered for a patient to get on with their life. ${ }^{60,61}$ The patients with FM had expected medical explanations to their bodily sensations and receive guidance on how to act. ${ }^{62}$ However, health professionals, diagnosis and clinical assessments provide little explanation enabling a patient to understand how to reconnect the strange body to a daily life and social roles. ${ }^{35,45}$

Both health professionals and lay persons interpret acute pain as a signal of bodily injury or pathology, and often this interpretation is transferred to a chronic pain condition. Patients with FM are told by health professionals to listen to their body signals in order to learn what they can and cannot do. There are a number of daily activities that can aggravate pain in FM, and what is easy to do one day can be impossible the following day. ${ }^{36}$ In interpreting aggravation of symptoms as a signal of injury it does not necessarily provide any definite answer about how to reconnect body and daily life. ${ }^{63}$ It might lead to avoidance of several activities and be constantly on guard to balance daily life to symptoms, ${ }^{39}$ and patients may strive to find a balance to make each day tolerable. ${ }^{27,31,35}$ This means that patients apply a number of strategies to accept the new situation, perform several adjustments in daily life that in turn may alter social roles and identities. Thus, patients undergo profound and complex processes. When health professionals consider them as malingerers and more or less give them up, they feel rather lonely in their strive to manage. ${ }^{49}$ Mannerkorpi and co-workers ${ }^{33}$ have described different patterns of living with FM. Some patients overachieve by struggling to live more or less as before, by mobilising all their physical and mental strength to fight their symptoms. Others adapt their everyday activities to pain from day to day, and some give up and allow pain to immobilise them. These findings suggest that either the patients spend their efforts to live a life to meet what is socially expected of them, or they give up and let symptoms rule their lives. 
Despite that FM is an incurable illness that patients have to learn to live with, it is reported that in clinical samples, almost half of the patients with FM no longer fulfil the criteria at a later follow-up. ${ }^{64,65}$ One epidemiological study from $\mathrm{UK}^{66}$ and another from Sweden ${ }^{67}$ show that about $15 \%$ of those with chronic widespread pain at a particular time no longer had widespread pain two or three years later. ${ }^{67}$ Thus, at least in some patients, pain may either vary considerably or disappear, and accordingly there can be a better prognosis for patients with FM than usually assumed. Those having succeeded to become healthy again have also been approached in qualitative studies; and twenty-three former female patients in three different countries have been interviewed. ${ }^{29,31,49,68-70}$ In one study, the women who had recovered refused to view pain as a signal of injury, but reinterpreted it as the body's way of warning about too much mental and physical strain over time. ${ }^{49}$ This interpretation helped them to apply the body signals as a resource to evaluate their life situation in a time span and adjust everyday life for a while to recover again. ${ }^{49}$ Also Wentz $^{69}$ and Sallinen et al ${ }^{29}$ suggest that modifying stress was important for recovering. Recently, the process of being in recovery was examined. ${ }^{31}$ When falling ill, the life situation became chaotic and unmanageable, ${ }^{68}$ but by exploring own experiences the informants gradually found out what could be tolerated of daily exposures. ${ }^{31}$ In this way, the informants developed a body awareness that helped them to recover and stay healthy. ${ }^{31,68}$ The women had spent years to recover, but during the time they experienced good days in between which they had to enjoy, and they noticed that a normal tiredness gradually replaced their fatigue. ${ }^{31}$ These insights created hope for further improvements and motivated them to carry on. Hope could also be raised by doctors telling that they had seen patients becoming healthy again. ${ }^{49}$ The process of exploring what their body could tolerate and how life could possibly be lived was both lonely and strenuous. ${ }^{68}$ One may say, however, that over time a coherence between body, self and social life were recreated. 


\section{Possible implications for physiotherapy practice}

This narrative review reveals how complex and challenging it is to live and become better from FM from patients' perspective. Unfamiliar, unpredictable symptoms disturb everyday life and makes daily life unmanageable. The patients are told to live with it, but the challenge is to understand how symptoms intersect with everyday life in order to get the life back on track again.

In accord with medical tradition, also within physiotherapy, interventions are tailored to normalize losses and promote healthy behaviour. For example, exercise programs are directed to reduce muscle weakness, deconditioning and to change an inactive life style. It is beneficial to increase physical capacity and stay physically active despite a chronic illness. However, as displayed in the present review, for a patient it might, at least in an early stage of FM, be pressing to find out how to make sense of the unfamiliar body and messy life situation caused by FM. In order to claim a life beyond illness, we suggest that it is important for the patient to find out how their body relates to routines, habits and social role expectations. It seems plausible that life cannot continue as before, but has to be adjusted to capability at the present and advance from there when the activity tolerance increases. In such an experiential personal learning process, we suggest that patients have to solve out what they can tolerate, what they will prioritize to do and what is not needed to do. This means that the patient has to play an active role, and the physiotherapist's role will be to act as a supportive councillor with the main focus on the patient's personal and social resources in remaking a tolerable life situation. A patient should become aware of and be encouraged to learn from own failures and success. Accordingly, the aim is not to normalize deficits, but to find opportunities to solve barriers met in the process of remaking a tolerable daily life. It does not necessarily mean that 
the aim is to return to what life was like before falling ill, but in terms of Mattingly ${ }^{71}$ personal healing means to a create a life worth living.

The findings reported from interviews of women having recovered from FM suggest that they have benefited from exploring own experiences to make sense of symptoms and how they intersect with activities in everyday life. This explorative process aligns with models of recovery-oriented practice. $^{72}$ The patient must accept the new limitations of daily life, temporarily adjust their lives, and try to use this as a starting point for gradually rebuilding a tolerable life worth living. Based on their expert knowledge about body and functioning, physiotherapists can give patients appropriate advice and support in the process of finding ways to make sense of body sensations and to manage or overcome obstacles in daily life. However, it is the patient who must determine the kind of life they will lead. This call for mobilisation of the patient's strengths, motivation and resources, and increasing the physical capacity by exercise might be appropriate to implement when the connection between symptoms and daily life becomes more comprehensible and manageable. Physiotherapists may find the counsellor role a challenge, since the patient's personal recovery process requires taking the complexity of being ill into account. The recovery process is not necessarily predetermined, nor does it follow a linear path. ${ }^{58}$ Patients may have to make up the rules as they go along, and their paths may take different turns over time. Seen in this light, a relapse does not necessarily have to be interpreted as a failure or aggravation of illness, but rather a breakthrough of developing new insights that opens up new possibilities for further progress. ${ }^{59}$ Of importance is to recognize and celebrate the small improvements to encourage the further process. For the patient, recovery includes self-development and personal growth.

Both patients and physiotherapists may become disappointed by the inefficacy of recommended therapies for FM, and physiotherapists may even become dismissive of patients 
with inexplicable pain conditions. ${ }^{73}$ In the previous paper, ${ }^{15}$ it was suggested to exercise and educate patients in pain-coping skills. Presently, this position is revised by suggesting that physiotherapists have to acknowledge that for a patient it is much more at stake than can be helped by practising pain-coping skills and exercise programs. Our close reading of qualitative studies has inspired us to highlight the importance that physiotherapists focus on the patient's explorative process in remaking an everyday life worth living.

\section{References}

[1] Queiroz LP. The world-wide epidemiology of fibromyalgia. Curr Pain Headache Report. 2013;17:356.

[2] Wolfe F, Clauw DJ, Fitzcharles MA Goldenberg DL, Häuser W, et al. Fibromyalgia criteria and severity scales for clinical and epidemiological studies: A modification of the ACR preliminary diagnostic criteria for fibromyalgia. J Rheumatol. 2011;38:1113-22.

[3] Yunus MB. Fibromyalgia syndrome: Clinical features and spectrum. J Musculoskel Pain. 1994;2:5-21.

[4] Mengshoel AM, Vøllestad NK, Førre Ø. Fatigue and pain induced by exercise in fibromyalgia patients and sedentary healthy subjects. Clin Exp Rheumatol. 1995;13:477- 82.

[5] Mannerkorpi K, Ekdahl C. Assessment of functional limitation and disability in patients with fibromyalgia. A literature review. Scand J Rheumatol. 1997;26:4-13.

[6] Chinn P, Caldwell W, Gritsenko K. Fibromyalgia pathogenesis and treatment options updates. Curr Pain Headache Reports. 2016; 20:25.

[7] Wolfe F, Smythe HA, Yunus MB, Bennett RM, Bombardier C, Goldenberg DL, et al. The American College of Rheumatology 1990: Criteria for the classification of fibromyalgia. Report of the Mulicenter Criteria Committee. Arthritis Rheum. 1990;33:160-72. 
[8] Undeland M, Malterud K. Diagnostic work in general practice: more than naming a disease. Scand J Prim Health Care. 2002;20:145-50.

[9] Macfarlane GJ, Kronisch C, Dean LE, Atzeni F, Häuser W, Fluß E, et al. EULAR revised recommendations for the management of fibromyalgia. Ann Rheum Dis. 2017; 76: 318-28.

[10] Üòeyler N, Häuser W, Sommer C. A systematic review on the effectiveness of treatment with antidepressants in fibromyalgia syndrome. Arthr Rheum. 2008;59:1279-98.

[11] van Koulil S, Effting M, Kraaimaat FW, van Lankveld W, van Helmond T, Cats H, et al. Cognitive-behavioural therapies and exercise programmes for patients with fibromyalgia: state of the art and future directions. Ann Rheum Dis. 2007;66:571-81.

[12] Bernardy K, Klose P, Busch AJ, Choy EH, Häuser W. Cognitive behavioral therapies for fibromyalgia. Cochr Database System Reviews. 2013;10 sept.

[13] Nuesch E, Häuser W, Bernardy K, Barth J, Juni P. Comparative efficacy of pharmacological and non-pharmacological interventions in fibromyalgia syndrome: network meta-analysis. Ann Rheum Dis. 2013;72:955-62.

[14] Brage S, Ihlebaek C, Natvig B, Bruusgaard D. Musculoskeletal disorders as causes of sick leave and disability benefits. Tidsskr Nor Lægeforen. 2010;130:2369-70.

[15] Mengshoel AM. Physiotherapy management of fibromyalgia: what do we know and how may this affect clinical practice? Phys Ther Rev. 2000;5:81-7.

[16] Mengshoel AM, Sim J, Ahlsen B, Madden S. Diagnostic experiences of patients with fibromyalgia - A meta-ethnography. Chron Illn. 2017; doi: 10.1177/1742395317718035. [Epub ahead of print]

[17] Bury M. Health and illness. 1.ed. Cambridge: Polity Press; 2005.

[18] Bury M. Chronic illness as biographical disruption. Sociol Health Illn. 1982;4:167-82. 
[19] Bury M. The sociology of chronic illness: a review of research and prospects. Sociol Health Illn. 1991;13:451-68.

[20] Taylor D, Bury M. Chronic illness, expert patients and care transition. Sociol Health Illn. 2007;29:27-45.

[21] Corbin JM. The body in health and illness. Qual Health Res. 2003;13:256-67.

[22] Cunningham MM, Jillings C. Individuals' descriptions of living with fibromyalgia. Clin Nurs Res. 2006;15:258-73.

[23] Hellström O, Bullington J, Karlsson G, Lindqvist P, Mattson B. A phenomenological study of fibromyalgia. Patient perspectives. Scand J Prim Health Care. 1999;17:11-6.

[24] Råheim M, Håland W. Lived experience of chronic pain and fibromyalgia: Women's stories from daily life. Qual Health Res. 2006;16:741-61.

[25] Lempp HK, Hatch SL, Carville SF, Choy EH. Patients' experiences of living with and receiving treatment for fibromyalgia syndrome: a qualitative study. BMC Musculoskel Dis. 2009;10:124.

[26] Arnold LM, Crofford LJ, Mease PJ, Burgess SM, Palmer SC, Abetz L, Martin SA. Patient perspectives on the impact of fibromyalgia. Pat Ed Couns. 2008;73:114-20.

[27] Hallberg LRM, Bergman S. Minimizing the dysfunctional interplay between activity and recovery: A grounded theory on living with fibromyalgia. J Qual Studies Wellbeing Health. 2011;6:7057.

[28] Dennis NL, Larkin M, Derbyshire SWG. "A giant mess"- making sense of complexity in the accounts of people with fibromyalgia. Br J Health Psychol. 2013;18:763-81. 
[29] Sallinen M, Kukkurainen ML, Peltokallio L, Mikkelsson M, Anderberg UM. Fatigue, worry, and fear - life events in the narratives of women with fibromyalgia. Health Care Women Internat. 2012;33:473-94.

[30] Söderberg S, Lundman B, Norberg A. The meaning of fatigue and tiredness as narrated by women with fibromyalgia and healthy women. J Clin Nurs. 2002;11:247-55.

[31] Grape, HE, Solbrække, KN, Kirkevold M, Mengshoel AM. Tiredness and fatigue during processes of illness and recovery. A qualitative study of women recovered from fibromyalgia. Physiother Theor Pract. 2017; 33:31-40.

[32] Sallinen M, Peltokallio L, Mikkelson M. 'I'm tired of being tired' - fatigue as experienced by women with fibromyalgia. Adv Physiother. 2011;13:11-7.

[33] Mannerkorpi K, Kroksmark T, Ekdahl C. How patients with fibromyalgia experience their symptoms in everyday life. Physiother Res Internat. 1999;4:110-22.

[34] Richardson JC, Ong BN, Sim J. Experiencing and controlling time in everyday life with chronic widespread pain: a qualitative study. BMC Musculoskel Dis. 2008;9:3.

[35] McMahon L, Murray C, Sanderson S, Daiches A. "Governed by the pain": narratives of fibromyalgia. Disabil Rehabil. 2012;34:1358-66.

[36] Henriksson, C. Living with continuous muscular pain - patient perspectives. Part 1. Encounters and consequences. Scand J Caring Sci 1995; 9: 67-76.

[37] Schoofs N, Bambini D, Ronning P, Bielak E, Woehl J. Death of a lifestyle. The effects of social support and healthcare support on the quality of life of persons with fibromyalgia and or chronic fatigue syndrome. Orthop Nurs. 2004;23:364-74.

[38] Åsbring P, Närvänen AL. Patient power and control: A study of women with uncertain illness trajectories. Qual Health Res. 2004;14:226-40.

[39] Löfgren M, Ekholm J, Öhman A. "A constant struggle": Successful strategies of women in work despite fibromyalgia. Disabil Rehabil. 2006;28:447-55. 
[40] Richardson JC, Ong BN, Sim J. Experiencing chronic widespread pain in a family context: giving and receiving practical and emotional support. Sociol Health Illn. 2007;29:347-65.

[41] Richardson JC. Establishing the (extra)ordinary in chronic widespread pain. Interdisipl J Soc Stud Health, Illn Med. 2005;9:31-48.

[42] Rodham N, Rance N, Blake D. A qualitative exploration of carers' and patients' experiences of fibromyalgia: one illness, different perspectives. Musculoskel Care. 2010;8:68-77.

[43] Williams SJ. Chronic illness as biographical disruption or biographical disruption as chronic illness? Reflections on a core concept. Sociol Health Illn. 2000;22:40-67.

[44] Jutel A, Nettleton S. Towards a sociology of diagnosis: Reflections and opportunities. Soc Sci Med. 2011;73:793-800.

[45] Undeland M, Malterud K. The fibromyalgia diagnosis-hardly helpful for the patients? Scand J Prim Health Care. 2007;225:250-55.

[46] Madden S, Sim J. Acquiring a diagnosis of fibromyalgia syndrome: The sociology of diagnosis. Soc Theor Health. 2016;14:88-108.

[47] Briones-Vozmediano E, Vives-Cases C, Ronda-Pérez E, Gil-González D. Patients' and professionals' views on managing fibromyalgia. Pain Res Manage. 2013;18:19-24.

[48] Choy E, Perrot S, LeonT, Kaplan J, Petersel D, Ginovker A, Kramer E. A patient survey of the impact of fibromyalgia and the journey to diagnosis. BMC Health Serv Res. 2010;10:102.

[49] Mengshoel AM, Heggen K. Recovery from fibromyalgia - patients' own experiences. Disabil Rehabil. 2004;26:46-53.

[50] Durif-Bruckert C, Roux P, Rousset H. Medication and the patient-doctor relationship: a qualitative study with patients suffering from fibromyalgia. Health Expect. 2014;18:2584-94. 
[51] Homma M, Yamazaki Y, Ishikawa H, Kiuchi T. 'This really explains my case!': biographical reconstruction of Japanese people with fibromyalgia meeting peers. Health Sociol Rev. 2016;25:62-77.

[52] Raymond MC, Brown JB. Experience of fibromyalgia. Qualitative study. Can Fam Phys. 2000;46:1100-06.

[53] Hallberg LRM, Carlsson SG. Psychosocial vulnerability and maintaining forces related to fibromyalgia. Scand J Caring Sci. 1998;12:95-103.

[54] Paulson M, Danielson E, Söderberg S. Struggling for a tolerable existence: The meaning of men's lived experiences of living with pain of fibromyalgia type. Qual Health Res. 2002; 12 : 238-49.

[55] Söderberg S, Lundman B, Norberg A. Struggling for dignity: The meaning of women's experiences of living with fibromyalgia. Qual Health Res. 2001;9:575-87.

[56] Åsbring P, Närvänen AL. Women's experiences of stigma in relationship to chronic fatigue syndrome and fibromyalgia. Qual Health Res. 2002;12:148-60.

[57] Juuso P, Skär L, Olsson M, Söderberg S. Meanings of being received and met by others as experienced by women with fibromyalgia. Qual Health Res. 2014;24:1381-90.

[58] Kearney MH. Understanding women's recovery from illness and trauma. Thousand Oaks: Sage Publications; 1999.

[59] Ralph OR, Corrigan PW. Recovery in mental illness. Broadening our understanding of wellness. Washington DC: American Psychological Association; 2002.

[60] Radley A. Making sense of illness. The social psychology of health and disease. Thousand Oaks: Sage; 2004. 
[61] Antonovsky A. Hälsans mysterium (Unraveling the mystery of health). 1 ed. Köpning, Sweden: Bokförlaget Natur och Kultur; 2000.

[62] Harding G, Parsons S, Rahman A, Underwood M. "It struck me that they didn't understand my pain": The specialist pain clinic experience of patients with chronic musculoskeletal pain. Arthr Rheum. 2005;53:691-6.

[63] Richardson JC, Ong BN, Sim J. Remaking the future:contemplating a life with chronic widespread pain. Chron Illn. 2006;2:209-18.

[64] Granges G, Zilko P, Littlejohn GO. Fibromyalgia syndrome: Assessment of the severity of the condition 2 years after diagnosis. J Rheumatol. 1994;21:523-9.

[65] Ledingham J, Doherty S, Doherty M. Primary fibromyalgia syndrome - an outcome study. Br J Rheumatol. 1993;32:139-42.

[66] Macfarlane GJ, Thomas E, Papageorgiou AC, Schollum J, Croft P, Silman AJ. The natural history of chronic pain in the community: A better prognosis than in the clinic? J Rheumatol. 1996;23:1617-20.

[67] Bergman S, Herrström P, Jacobsson LTH, Petersson IF. Chronic widespread pain. A three year followup of pain distribution and risk factors. J Rheumatol. 2002;29:818-25.

[68] Grape HE, Solbrække KN, Kirkevold M, Mengshoel AM. Staying healthy from fibromyalgia is ongoing hard work. Qual Health Res. 2015;25:679-88.

[69] Wentz KAH. Women with fibromyalgia: Distress avoidance interferes with gaps in pain. J Pain Manage. 2012;5:245-59.

[70] Wentz KAH, Lindberg C, Hallberg LRM. On parole: The natural history of recovery from fibromyalgia in women.: A grounded theory study. J Pain Managment. 2012;5:177-94. 
[71] Mattingly C. Healing dramas and clinical plots. The narrative structure of experience. Cambrige: Cambridge University Press; 1998.

[72] Roberts G, Boardman J. Becoming a recovery-oriented practitioner. Adv Psych Treatm. 2014;20:37-47.

[73] Sanders T, Foster NE, Bishop A, Ong BN. Biopsychosocial care and the physiotherapy encounter: physiotherapists' accounts of back consultations. BMC Musculoskel Dis. 2013;14: 65 . 
Table 1. Literature search terms

Search terms were; fibromyalgia AND qualitative OR lived OR life OR living OR interview* OR narrative* OR narration* OR semi structured OR thematic OR focus OR open ended OR grounded OR emic OR etic OR hermeneutic* OR semiotic* OR data saturation OR social OR post structural* OR poststructural* OR cooperative inquir* OR co operative inquir* OR humanistic OR existential OR experiential OR paradigm OR field OR ethnonursing OR action research OR observ* OR phenomenol* OR subjective OR story OR stories OR experience*. 